\title{
Chinese TV Advertising Creation in Cross-cultural Communication in the Big Data Era
}

\author{
Zhuo Jin \\ Bozhou University \\ Bozhou, China \\ Marine Convergence Design \\ Pukyong National University \\ Busan, Republic of Korea
}

\author{
Chunggun Jang \\ Dept. of Visual Design \\ Pukyong Pukyong National University \\ Busan, Republic of Korea
}

\begin{abstract}
With the continuous development of China's economy and technology, the development of the internet industry has made great progress. All people began to come into contact with the network. The development of the internet impacts on various industries, and our living habits and consumption habits are also subject to the impact of the internet. From the beginning of 2015, China ushered in the tide of the internet, which makes each industry active or passive to meet the new changes. Among them television advertising is a very typical example, especially the Chinese creative advertising culture in cross-cultural communication.
\end{abstract}

Keywords - the big data era; cross-cultural communication; Chinese TV advertising creation

\section{INTRODUCTION}

The development of the national economy and the progress of science and technology often lead to cultural changes, especially in current environment of economic globalization. If the development of economy and the progress of science and technology are independent from culture, they will become feeble and futile. At the same time, it is also a standard to measure the comprehensive strength of a country whether the development of economy and technology can drive the culture promotion or not. As one part of culture, TV advertising creation occupies a space in the current era. TV, as a traditional mainstream media, is still indispensable, though the media styles in the Internet era are innovated and changed repeatedly. We should be glad that TV has not been eliminated. This imaging tool that has accompanied us most of our daily life is not abandoned by the era. On contrary, it becomes stronger with the demand characteristics that internet media do not have. TV ads occupy a larger space of TV content. With the changes of people's appreciation level and the way of life, people gradually change their attitude on TV ads from hating to love. The proper appearance of TV ads eases the fatigue of televiewers and makes them get latest product information. Even some creative ads can be a surprise to televiewers. These ads can meet the demand of televiewers to seek novelty. The coming of big data era puts a higher requirement for Chinese TV advertising creation in cross-cultural communication, but also provides new opportunities. It requires putting more sincere cost on Chinese TV advertising creation in crosscultural communication, and making it more suitable for televiewers' appreciation level and consumer psychology. If Chinese TV ads are made excellent in cross-cultural communication, they will have more communication energy and advertising value in the big data era.

\section{A REVOlution of CHINESE TELEVISION AdVERTISING CREATION IN CROSS-CULTURAL COMMUNICATION BROUGHT BY THE BIG DATA ERA}

\section{A. What is the Big Data Era?}

"Big data" was first put forward by a global consultancy McKinsey \& Co. McKinsey said: "data have fused into every industry and business function category today, and become one of the important production factors". When people deeply analyze and use a variety of massive data, it will bring a new increase of production and operation efficiency and the real coming of consumer surplus era. Big data have been applied in various fields, and some industries begin to massively use this means of production. The numerous successful cases and achievements announced the coming of the big data era. After the time of fermentation and propagation of information, big data constantly attract attention of more industries and groups. The term of big data is mentioned and discussed on many important occasions more times. People use it to define and generalize massive data produced by information explosion. We attach importance to big data, and the era of big data returns us three overturning changes of concepts, including: first, it is all data rather than sampling data; second, it is general direction rather than accurate specific guidance; last, it is correlativity rather than general causality.

\section{B. The Influence of Big Data Era on Chinese TV Advertising Creation in Cross-Cultural Communication}

Chinese TV advertising creation in cross-cultural communication has received much attention since its birth. This advertising means has been favored by all industries. Chinese TV advertising creation in cross-cultural communication cannot represent the highest level of advertising creation, but it can be a professional standard to measure the level of advertising effect. With the great change on televiewers, and the increase of their appreciation level, it is undoubtedly a better industrial innovation and a reliable choice 
to use cross-cultural communication as communication means of TV advertising creation.

But with the development of times, the big data era carried by Internet quietly comes to all walks of life, including the advertising industry. How to keep update of creation and increase of achievements in the flood of big data era is an unavoidable epoch topic confronting the advertising industry. Though our advertising industry is still on a prosperous upward stage, and our TV advertising creation in cross-cultural communication emerges one after another, it is the first time for us to standing in such a macro environment. The era of big data has magic speed of propagation. Good advertising products can be spread rapidly. The efficiency can be enlarged innumerably in information value of big data. But meanwhile, it also has a negative factor that if the advertising is not successful, it will be eliminated and perished in the repeat screening of big data and in spread. This double-edged spread model can make the good advertising creation create more benefits, and make unsuccessful advertising creation to be caviled and rejected by big data. Therefore, if Chinese TV advertising creation in cross-cultural communication wants to follow the pace of the times, it should use correct methods in order to get recognition of market and usher in a golden development period. If it still follows the beaten track and ignores the influence of internet and big data, it will be eliminated by the market.

\section{THE StATUS OF ChINESE TV ADVERTISING CREATION IN CROSS-CULTURAL COMMUNICATION IN THE BIG DATA ERA}

\section{A. Paying Attention to Cross-Cultural Communication, but Ignoring the Information Changes in the Big Data Era}

Chinese TV advertising creation in cross-cultural communication tends to go into a blind area that it pays attention to the value of the cross-cultural communication but ignores changes of information. At present, our TV advertising creation has such a characteristic. Cross-cultural communication is a kind of creative advertising means. It has been well known by the industry practitioners. It is an open secret. If it still remains on this old road, it will lose more than it gains in current big data era.

Takes an advertisement of world famous Nippon Paint Group as an example. The advertisement of Nippon Paint, called "Dragon", was published on page 48 of International Advertising. There is a Chinese traditional pavilion in the picture. Two dragons twine separately on the two columns of the pavilion. The left column is in dark color, and the dragon tightly clings to the column. The right column is in bright color, and the dragon fell to the ground. Besides the picture there is a description that the right column is painted with Nippon paint, so the dragon slipped and fell. Industry experts said: this creation is great. It dramatically manifests the characteristics of the product. It is a perfect example to combine advertising creation with surrounding environment." But behind the surface perfect is a major crisis, because some Chinese people thought it damaged the image of Chinese dragon. This designer tried to be different. But with the wide spread of this negative information in various media, it set off a wave of social discussion and incurred public condemn. This advertisement brought such a consumption reaction. Will consumers accept the product on the ad? Undoubtedly this creative advertising is a failure. It is in cross-cultural communication, but it didn't deal with the relationship between culture and advertising well, and didn't fully take the digital spread of information in now times. So, the creation failed and the company had to pay public relation cost.

\section{B. Paying More Attention to Product Rendering than to the Reform of The Methods}

Our current advertising creation generally has such characteristic. Advertising companies strongly use advertising to render product functions, and few of them focus on innovation of advertising methods. As the saying goes, "change and pass, and then survive". The author of this saying has gone for a long time. The meaning of this saying is not weakened with the development of times. On contrary, in current times, it becomes more practical. Of course, advertising cannot go without the introduction to product attributes. But if there is innovative method as carrier, this advertising creation will eventually be eliminated by the times no matter due to the TV advertisement receivers' aesthetic fatigue or the intense competitive environment.

All TV advertisements we see today, regardless of the length of time, use colors to render the product functions. The standpoint of this creation is to introduce product's functions in all directions. Better advertising creation may shape value of the product. But it often ignores the advertising forms. Stereotyped advertising contents ram eyes of televiewers. But they are more willing to close their eyes and have a rest or go to the restroom during this time. It is not an individual phenomenon but a true portrayal of reality.

\section{Starting from the Angle of Product Rather than the Angle of Consumers}

If we carefully analyze the unsuccessful cases of Chinese TV advertising creation and advertising cases without a sensational effect, it is not difficult to find the reason of failure that advertising creation is made from the angle of product rather than the angle of consumers. It is a problem of angle, but the result can be quite different. At present, many of our Chinese TV advertising creations are still wandering in this misunderstanding.

The product is the protagonist of advertisement, but it is not in marketing. The protagonist of marketing is consumer. The ultimate goal and stance of product are still in marketing. Without marketing it cannot be called as product. It can only be called as trash. The purpose of manufacturers to put up advertisements is to make their products enter into marketing channel and get profits. If we do not deal with this relationship well in TV advertising creation, it may easily cause zero income or even negative return. 


\section{The Strategies of Chinese TV AdVERTISING CREATION IN CROSS-CULTURAL COMMUNICATION IN THE BIG DATA ERA}

\section{A. To Create Something New and Original and Focus on the Most Differentiated Attribute of the Product}

Entering in the big data era, the targeted receivers of television advertisement and its media function have changed. With the fast transmission of data and convenient information, Chinese TV advertising creation in cross-cultural communication should be new and original. Our advertising creation shall be designed with elements of cross-cultural communication and of peculiar types, which can give consumers a sense of freshness. They shall not be easily imitated or surpassed by competitors. It is the key point that our television advertising practitioners need to consider in the big data era. At the same time, our creation should focus on product value and present the most differentiated attribute of the product. It is not wise to present all functions of product in one piece of ad in a few minutes, because it will make a sense of disorder in the minds of consumers. If we use the method of focus introduction and unique advertising form to deliver the special attribute of product, the effect of our advertising creation will be doubled.

Take the advertisement of NongFu Spring as an example. In recent two years, NongFu Spring has kept put such a piece of cross-cultural communication TV advertisement that the Tibetan staff of NongFu Spring take pains to deliver NongFu spring to thousands of households. The advertisement fully shows the simple and pure character of Tibetans, meanwhile it also delivers the attribute of NongFu spring. That is the only water source. The advertisement doesn't render the package of the bottle, doesn't advertise the price of the product, and doesn't overstate the attribute of their mineral water. It only focuses on water source. It is leisurely like a story which goes into the mind of consumers and leaves them a deep impression. It is a great success.

\section{B. To Deliver Information and Use the Orderliness of Information to Create A Unique Advertising Atmosphere}

We cannot refuse this information age. Even one does not integrate to the big data era will perish. Chinese TV advertising creation in cross-cultural communication is given with higher requirements. It requires advertising practitioners to know, use and deliver information well. To deliver information should not be a simple feature but an important feature of television advertisement. Only by better delivering information and using orderliness of information can Chinese TV advertising creation in cross-cultural communication create a unique advertising atmosphere. This atmosphere is more likely to be admitted and accepted by consumers and it is not easy to be swallowed by the tide of information.

Chinese television advertising creation in cross-cultural communication itself is a powerful information complex. It should consider cultural differences and the acceptance level of different cultural groups into account. Information can often be a universal language. Information has the characteristics of shortness, smallness and easy identity, so it can be used as means of Chinese TV advertising creation in cross-cultural communication. Seen from the creative ad of Augerta, highend product of Tsingtao Brewery, the effective use of information is easy to make a success. The advertisement focuses on cross-cultural communication, such as, Germany's centennial yeast, typical royal formula, and starting from the year of 1903. One piece of ad used a lot of data and information, which represents the centurial brewing. Consumers are easier to be moved to buy Augerta.

\section{To Enhance the Timeliness of Cross-Cultural Communication}

The typical feature of the big data era is "fast". Chinese TV advertising creation should consider the timeliness of ad which includes the length of time, reasonability of figure setting in the ad and other factors. It should not only maximize the effectiveness of ad in a short time, but also avoid failure due to long content or change of product and main figure. In 2008 Nike invited World Champion Liu Xiang to advertising their products. At first, the effect was good. But when Liu Xiang suffered a setback in 2008 Olympic Games, the cross-cultural communication advertising creation became invalid and the ad effect was far lower than expected. Therefore, TV advertising practitioners shall have the ability to assess the timeliness of ad to avoid risks.

\section{To Carry out the Advertising Creation with Consumer as the Core and Market Demand as the Direction}

Consumers are the receivers of TV advertisement in crosscultural communication, and the key influencers who can help product realize its value from use value. It requires TV advertising practitioners to take consumer as core and market demand as direction in ad strategy design. They should pay attention to changes in consumer habits and market trends, because in the era of big data, this subtle change may be analyzed specifically and thoroughly. We need use big data to make our management more convenient and fast and realize digital analysis of changes of consumers and market, so as to direct our TV advertising creation design. In this way we can really achieve cross-cultural communication and make it serve consumers, products, market and enterprises.

\section{CONCLUSION}

The coming of big data era makes Chinese TV advertising creation in cross-cultural communication wonderful and brilliant. But due to the characteristics of big data era, it also makes it look flat and direct. The examination level of market is increasingly improved because of big data. Therefore, TV advertising practitioners shall take changes of industrial environment into consideration in designing cross-cultural communication. In addition, they should study consumer appreciation habits and market demand trends, and be able to get and use information well in the big data era, so that they can make Chinese television advertising creation in crosscultural communication stand in an invincible position and contribute more excellent TV ads for Chinese television advertising industry. 


\section{REFERENCES}

11] Liu Linsha \& Jane Zhu. Practical Teaching Reform of Advertising Based on Science and Engineering Background. Young Reporter, 2013 (6)

[2] William F Arens [America]. Translated by: Ding Junjie, Cheng Ping, Yuan Fei \& Zhang Xi. Contemporary Design Advertising. Huaxia Publishing House, 2010.

[3] Li Guojie. Big Data Research. Chinese Computer Association Newsletter, 2012. 